\title{
Índice de satisfação do sistema de abastecimento hídrico na zona urbana de Pau dos Ferros/RN
}

O presente trabalho teve por objetivo analisar o índice de satisfação dos serviços do sistema de abastecimento hídrico ofertados a população da zona urbana de Pau dos Ferros/RN, a fim de construir um panorama de ações necessárias para garantia de uma melhor qualidade de vida dos moradores e eficiência do sistema na localidade. A disponibilidade de água para a população consiste num serviço essencial para a manutenção da vida humana e suas diversas atividades, só que vem sendo comprometido devido ações antrópicas, descontinuidade, abrangência, qualidade disponibilizada. Dessa forma, a pesquisa consistiu em uma aplicação de questionários para a coleta de dados primários direcionado a população amostral de domicílios de 17 bairros da zona urbana do município supracitado, que quantificou a percepção do nível de satisfação do serviço prestado. Verificou-se que $65 \%$ dos bairros em análise possuem o nível baixo de satisfação, $35 \%$ classificaram como médio, não havendo registro de alto nível. Constatou-se, por meio do estudo, a necessidade de criar um plano mais preciso de gestão hídrica e necessidade de melhoria na eficiência deste serviço básico, além da necessidade de se estabelecer um gerenciamento voltado a atender de forma preventiva, mediante a promoção do monitoramento das estruturas e do sistema.

\section{Satisfaction index of the water supply system in the urban area of the city of Pau dos Ferros/RN}

\begin{abstract}
The main goal of this study was to analyze the satisfaction index of water supply system services offered to the population of the urban area of Pau dos Ferros/ $\mathrm{RN}$, in order to build an overview of the actions needed to ensure a better quality of life for the residents and the efficiency of the system in the locality. The availability of water for the population is an essential service for the maintenance of human life and its various activities, however it has been compromised due to anthropic actions, discontinuity, scope, and available quality. Therefore, this research consisted of applying questionnaires to collect primary data targeting samples of households in 17 neighborhoods in the urban area of the mentioned municipality, which quantified the population perception of the level of satisfaction of the service provided. It was found that $65 \%$ of the neighborhoods under analysis have a low level of satisfaction, $35 \%$ classified it as medium, and there was no high-level recorded. Thus, through this study it was noted the need to create a more accurate water management plan and the need to improve the efficiency of this basic service, in addition to the need to establish management aimed at providing preventive care, by promoting the monitoring of structures and the system.
\end{abstract}

Keywords: Rational Management; Environmental Health; Environmental Perception.

Francisco Soares Roque (iD

Universidade Federal Rural do Semi-Árido, Brasil http://lattes.cnpq.br/4466838919204802 http://orcid.org/0000-0003-3524-2344 fabiokand@gmail.com

Joel Medeiros Bezerra (iD

Universidade Federal Rural do Semi-Árido, Brasil http://lattes.cnpq.br/6945041178312614 http://orcid.org/0000-0002-8150-4125 joel.medeiros@ufersa.edu.br

Bruna Monallize Duarte Moura (iD) Universidade Federal Rural do Semi-Árido, Brasil http://lattes.cnpq.br/3543246051549223 http://orcid.org/0000-0003-0599-4131 bruna.monallize@gmail.com
Talita Tássia da Costa (D)

Universidade Federal Rural do Semi-Árido, Brasil http://lattes.cnpq.br/0751541426540864 http://orcid.org/0000-0001-6912-8932 talitatcosta@hotmail.com

\section{Alana Ticiane Alves do Rêgo (iD}

Universidade Federal Rural do Semi-Árido, Brasil http://lattes.cnpq.br/6783254406806614 http://orcid.org/0000-0001-9005-2610 alana ticiane10@hotmail.com

Rafael Silva de Souza (iD)

Universidade Estadual do Rio Grande do Norte, Brasil http://lattes.cnpq.br/5061185846392673 http://orcid.org/0000-0001-8689-8189 rafael2100cruzada@hotmail.com

\author{
Helves Clerverton Guerra Costa (iD) \\ Universidade Federal Rural do Semi-Árido, Brasil \\ http://lattes.cnpq.br/9052627585320406 \\ http://orcid.org/0000-0002-4895-6840 \\ helves.guerra5@gmail.com \\ Antonio Batista Queiroz Júnior (iD \\ Universidade Federal Rural do Semi-Árido, Brasil \\ http://lattes.cnpq.br/6882297538884280 \\ http://orcid.org/0000-0003-3911-3881 \\ antonio.queiroz17@gmail.com \\ Ricassilly Isac Bruno Rufino Lima (iD \\ Universidade Federal Rural do Semi-Árido, Brasil \\ http://lattes.cnpq.br/1677458778246978 \\ http://orcid.org/0000-0002-6096-4827 \\ ricassilly@hotmail.com
}

\section{Referencing this:}

ROQUE, F. S.; BEZERRA, J. M.; MOURA, B. M. D.; COSTA, T. T.; RÊGO, A. T. A.; SOUZA, R. S.; COSTA, H. C. G.; QUEIROZ JÚNIOR, A. B.; LIMA, R. I. B. R.. Índice de satisfação do sistema de abastecimento hídrico na zona urbana de Pau dos Ferros/RN. Revista Ibero Americana de Ciências Ambientais, v.11, n.4, p.180-190, 2020. DOI:

DOI: 10.6008/CBPC2179-6858.2020.004.0016 http://doi.org/10.6008/CBPC2179-6858.2020.004.0016 


\section{INTRODUÇÃO}

A água é um recurso natural indispensável e essencial para a manutenção da vida dos seres vivos no planeta. O planeta Terra é composto de uma vasta quantidade de recursos hídricos, chegando a ser constituído por $97,5 \%$ de tal recurso. Todavia, desse total, apenas $3 \%$ está disponibilizada para utilização do homem (RIBEIRO et al., 2017). Tal situação acaba demostrando-se preocupante tendo em vista os múltiplos usos que esse bem oferece, sendo um recurso natural indispensável para a sobrevivência humana.

A importância da água está relacionada ainda a assegurar a sobrevivência dos seres vivos, além de garantir a manutenção no planeta, sendo assim toda a história do mundo é delineada por seu acúmulo ou ausência. Dessa forma, a quantidade de água disponibilizada está intrinsecamente relacionada com a sua qualidade, isto quando se trata de abastecimento humano, tornando-se características fundamentais para a manutenção da saúde humana e para o desenvolvimento das sociedades (LIBANIO et al., 2005; ANDRADE et al., 2019).

Devido a sua relevância na garantia da saúde e segurança das populações, a água se torna uma determinante ambiental que necessita de uma abordagem que perpasse todas as etapas do serviço de fornecimento de água, indo desde a sua captação no manancial até o consumidor final, adotando medidas de monitoramento de sua qualidade e compartilhamento das informações com todos os atores envolvidos no uso desse recurso (RONCALLI et al., 2019).

Os Sistemas de Abastecimento de Água (SAA), consistem em formas ou mecanismos de captação da água na natureza, tanto em mananciais subterrâneos, quanto nos superficiais. Para que ocorra de forma eficiente é necessário que o mesmo esteja adequado fornecendo água com padrão de potabilidade vigente estabelecido pela legislação (CUNHA et al., 2015). Sendo assim, é necessário que essas ações comportem e atendam às necessidades de cada localidade para assim agir de forma eficiente. Em uma pesquisa contígua de 2012-2016 no Brasil, 87,3\% dos domicílios ligados à rede geral possuíam disponibilidade diária de água. No entanto, quando se analisa a região do Nordeste, o valor decai para $66,6 \%$, mostrando a falta de uniformidade na distribuição do recurso pelas regiões do país (IBGE, 2017).

De acordo com Martins et al. (2016), essa descontinuidade da qualidade de abastecimento hídrico nesta região tem influência direta diante do severo período de estiagem enfrentado nos últimos anos, que tem ocasionado a diminuição significativa no volume dos reservatórios e com isso exigido a necessidade de implantações de medidas emergenciais pelos poderes públicos de âmbito federal, estadual e municipal, para garantir o acesso deste serviço à população através da construções de adutoras, perfuração de poços e distribuição por carros pipas.

A Organização das Nações Unidas - ONU, defini como um dos seus 17 objetivos a necessidade de garantir uma gestão sustentável da água para todos como forma de assegurar qualidade de vida, ou seja, através do uso consciente com práticas de reuso e educação ambiental proporciona a disponibilidade adequada deste recurso (SILVA et al., 2019).

Diante desse contexto é necessário mensurar como está sendo disponibilizado o abastecimento de 
água desde quantidade, características, localidades e outros aspectos, para assim identificar este serviço e quando necessário propor medidas que possibilitem um acesso mais adequado (SALDANHA et al., 2016). Logo, o abastecimento hídrico para as populações, sejam urbanas e rurais, é um processo contínuo e que deverá ser universalizado para todos os brasileiros (LIMA, 2020).

Nesses termos, faz-se necessário a avaliação do índice de satisfação quanto ao fornecimento hídrico para identificar o nível em que se encontra o abastecimento de água no município de Pau dos Ferros, tendo em vista que a região se encontra no semiárido nordestino, onde a disponibilidade hídrica é escassa. Além disso, os dados obtidos poderão servir de base para o desenvolvimento de políticas públicas para sanar quaisquer problemas que por ventura sejam identificados.

Com base nisso, o presente trabalho propõe a análise do índice de satisfação dos serviços do sistema de abastecimento hídrico ofertados a população da zona urbana de Pau dos Ferros/RN, a fim de construir um panorama de ações necessárias para garantia de uma melhor qualidade de vida dos moradores e eficiência do sistema na localidade mencionada.

\section{METODOLOGIA}

\section{Tipologia da pesquisa}

A abordagem deste trabalho baseou-se em uma estratégia quali-quantitativa. Para Marconi et al. (2010), a pesquisa quali-quantitativa se trata de uma pesquisa que tem como premissa, analisar e interpretar aspectos mais profundos, descrevendo a complexidade do comportamento humano e ainda fornecendo análises mais detalhadas sobre as investigações, atitudes e tendências de comportamento.

Além disso, enquadra-se no ponto de vista de seus objetivos, como sendo uma pesquisa exploratória, visto que proporciona maior familiaridade com a problemática do município de Pau dos Ferros/RN em relação ao sistema de abastecimento hídrico, diante de uma abordagem de percepção social (PRODANOV et al., 2013).

Para a coleta de dados e execução da pesquisa foram adotados instrumentos como pesquisa bibliográfica, registros fotográficos, observação direta da área de estudo, investigação em documentos oficiais e entrevistas direcionadas a população que foram realizadas in loco ou através de formulários eletrônicos (GIL, 2008).

\section{Área de estudo}

O presente estudo foi conduzido no município de Pau dos Ferros, localizado na região semiárida nordestina do estado do Rio Grande do Norte. Conforme dados do censo do Instituto Brasileiro de Geografia e Estatística (DANTAS et al., 2015), a região de estudo possui uma população atual estimada em 30.394 habitantes, distribuída em uma área de $259,959 \mathrm{~km}^{2}$, equivalente a 0,52\% do território estadual.

O abastecimento de água da cidade de Pau dos Ferros é realizado pela Companhia de Águas e Esgotos do Rio Grande do Norte (CAERN), onde até o ano de 2015 era realizada a captação de água para o 
abastecimento da cidade por meio do Açude Dr. Pedro Diógenes, situado na cidade em apreço, e a posteriori ao chegar em seu volume morto encerrou suas atividades, passando a ser feito a partir da barragem de Santa Cruz em Apodi/RN (LEITE et al., 2019).

\section{Definição do tamanho da amostra}

O processo de amostragem populacional do referido estudo utilizou-se como fonte os dados fornecidos pelo escritório local de Pau dos Ferros da Companhia de Águas e Esgotos do Rio Grande do Norte (CAERN), referentes ao ano de 2018 do número de ligações ativas da zona urbana do município, distribuídas por bairro (Figura 1).

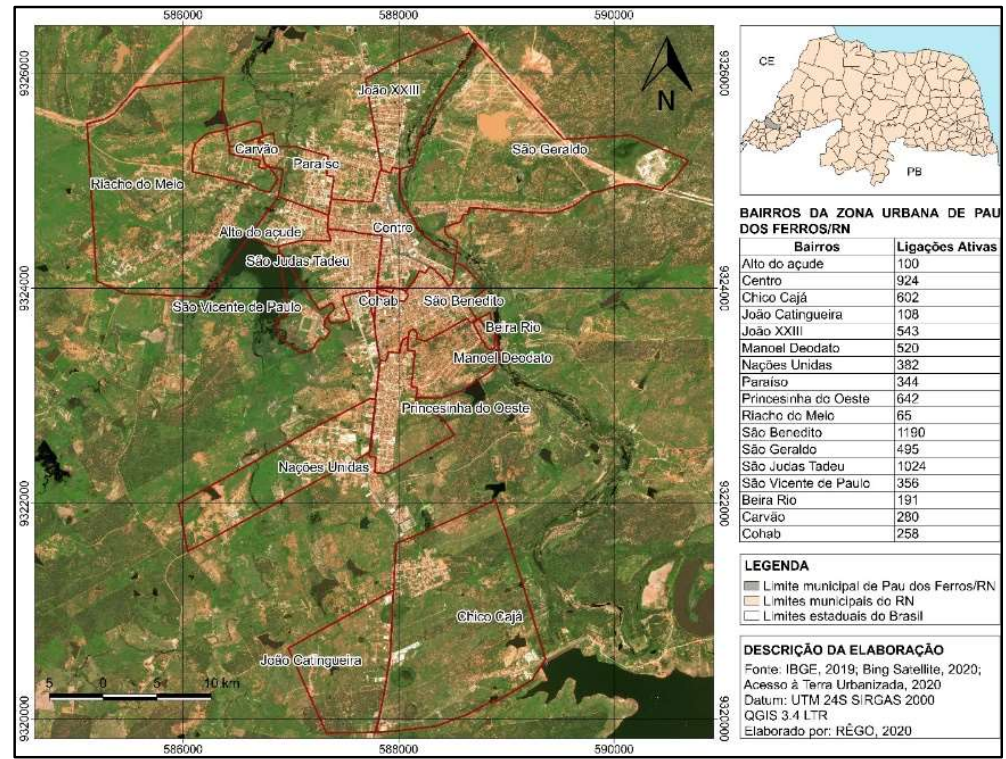

Figura 1: Distribuição dos bairros em análise da zona urbana do munícipio de Pau dos Ferros/RN.

Para o cálculo da amostra, utilizou-se a metodologia proposta por Martins (2006), que considera a variável nominal e a população finita, como também nível de confiança de $95 \%$ e a proporção $\widehat{p}$ igual 0,50. A realização dos questionários com a população foi realizada aleatoriamente nos domicílios inseridos nos bairros da zona urbana do município, de forma a contemplar uma maior totalidade da área de estudo.

Dessa forma, calculou-se a amostra representativa e obteve um valor mínimo equivalente a 367 questionários, segundo o número de ligações ativas nos 17 bairros em análise do município. No entanto, diante da acessibilidade da população, foram aplicados 398 questionários.

\section{Coleta e tratamento de dados}

No período entre os meses de junho e julho de 2018 ocorreu a aplicação dos questionários in loco e por meio de formulário eletrônico com perguntas objetivas para a coleta de dados direcionado a população amostral de domicílios de 17 bairros distintos da zona urbana do município de Pau dos Ferros/RN. O questionário aplicado aos participantes foi composto de perguntas fechadas que objetivaram determinar o índice de satisfação dos usuários do abastecimento de água no município de estudo. Para tanto, foi submetido aos entrevistados questionamentos sobre a existência ou não de abastecimento pela CAERN, com 
que frequência esse abastecimento ocorre, se é utilizado outra forma de abastecimento e qual o grau de satisfação pelo serviço prestado.

Com as informações obtidas, as respostas foram agrupadas em categorias por meio de análise das descrições acerca do questionamento e depois quantificadas de acordo com o nível de satisfação do serviço prestado. Para o tratamento dos dados fez utilização de técnicas de estatística simples e dados plotados em gráficos, com o auxílio do software Microsoft Excel versão 2016. Esse processo é esquematizado na Figura 2.

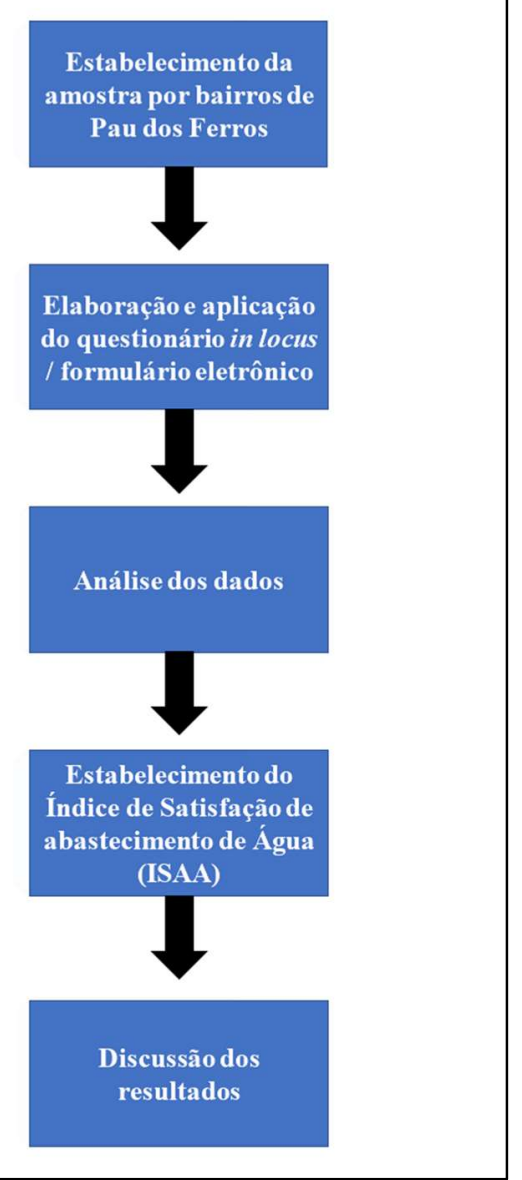

Figura 2: Fluxograma da metodologia para análise do Índice de Satisfação de Abastecimento de Água (ISAA) no município de Pau dos Ferros/RN.

\section{Índice de satisfação do sistema de abastecimento de água}

De acordo com Brasil (2018), Pau dos Ferros abastece um percentual 92,03 \% da população local, diante disto, buscou-se exemplificar o grau de satisfação quanto a qualidade do sistema de abastecimento de água ofertado no município referido, conforme propõe metodologia de Menezes Filho et al. (2017). Em outras palavras, corresponde a análise da média ponderada entre as respostas de alta satisfação (soma de muito satisfeita e satisfeita) dotada de peso 1 e a média (pouco satisfeito) com peso de 0,5 , como elucida-se na Equação 1.

$$
I S A A=\frac{R \operatorname{alta}(M S+S) * 1+R \text { média }(P S) * 0,5}{\text { Rtotal }}
$$


ISAA = Índice de Satisfação do Sistema de Abastecimento de Água; $\mathrm{R}$ alta = Respostas com alto nível de satisfação, considerando para isso alternativa muito satisfeita (MS) e satisfeita (S);

$\mathrm{R}$ média = Respostas com médio nível de satisfação, considerando para isso alternativa pouco nível de satisfação;

$\mathrm{R}$ total $=$ Soma de todas as respostas.

Como forma de analisar os dados obtidos optou-se por desenvolver um mapa temático com a espacialização desses dados para que pudesse facilitar a observação de tais resultados.

\section{RESULTADOS E DISCUSSÃO}

Na Figura 3 é possível observar o ISAA em cada bairro do município. Nota-se que este índice varia entre baixo e médio, de acordo com classificação proposta por Menezes Filho et al. (2017).

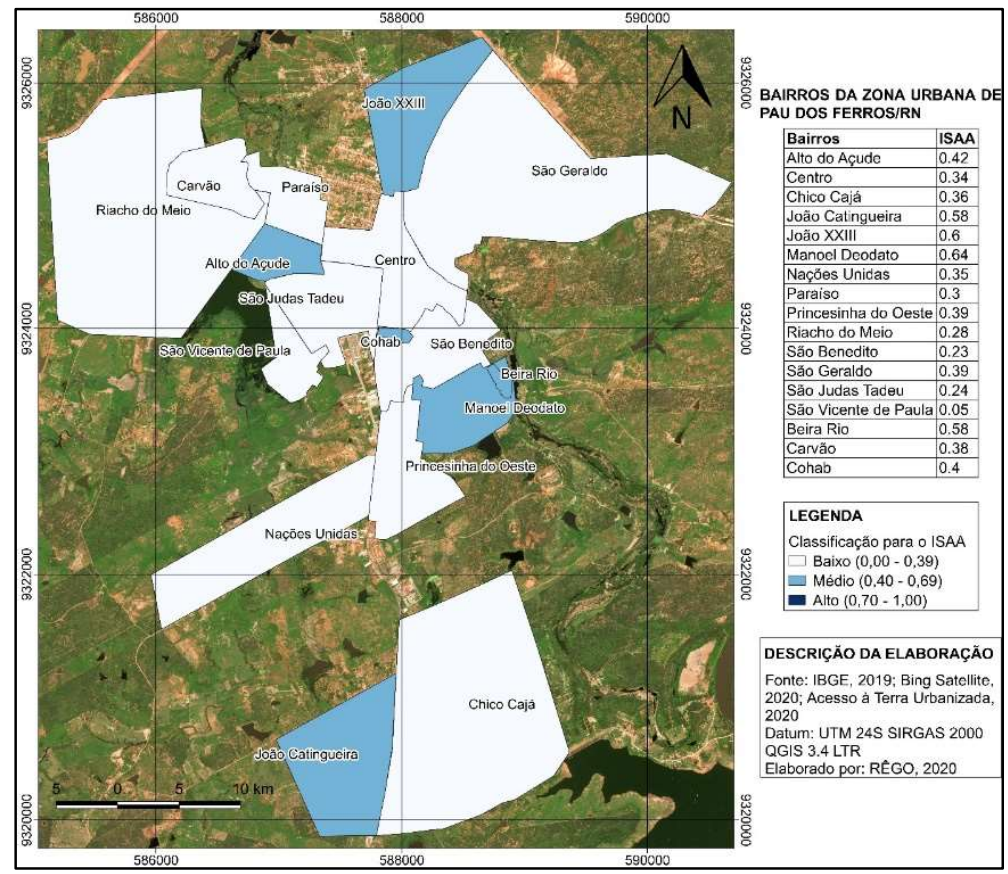

Figura 3: Índice de Satisfação de Abastecimento de Água por bairro do munícipio de Pau dos Ferros/RN, em 2018.

Conforme a Figura 3, 65\% dos bairros em análise possuem o nível baixo de satisfação, 35\% classificaram como médio e nenhum como alto. Destaca-se com menor índice o bairro São Vicente de Paula, com $5 \%$ aceitação ao nível dos serviços em estudo e com maior aceitação o bairro Manoel Deodato com $64 \%$.

A diferença de classificação entre os índices ressalta que o abastecimento ocorre de forma intermitente e não homogênea em todos os bairros, já que a eficácia deste serviço depende de um dimensionamento adequado para cada área que influencia diretamente nas condições da pressão de vazão mínima/máxima e equipamentos necessários para evitar perdas reais de água (MOTTA, 2010). Assim, o bairro Manoel Deodato por ter uma declividade maior que o São Vicente de Paula consegue ser abastecido mais rapidamente diante da setorização.

Ainda existem outros fatores que podem influenciar nessa insatisfação ou deficiência no abastecimento, como as perdas por vazamentos e ligações clandestinas, que quando somadas, tem-se um desperdício de 32 bilhões de $\mathrm{m}^{3}$ de água pós tratamento no mundo (TEIXEIRA et al., 2019). Quanto ao município de Pau dos Ferros, foi possível observar alguns vazamentos em algumas localidades que 
representam desperdício de água destinada ao abastecimento (Figura 4).

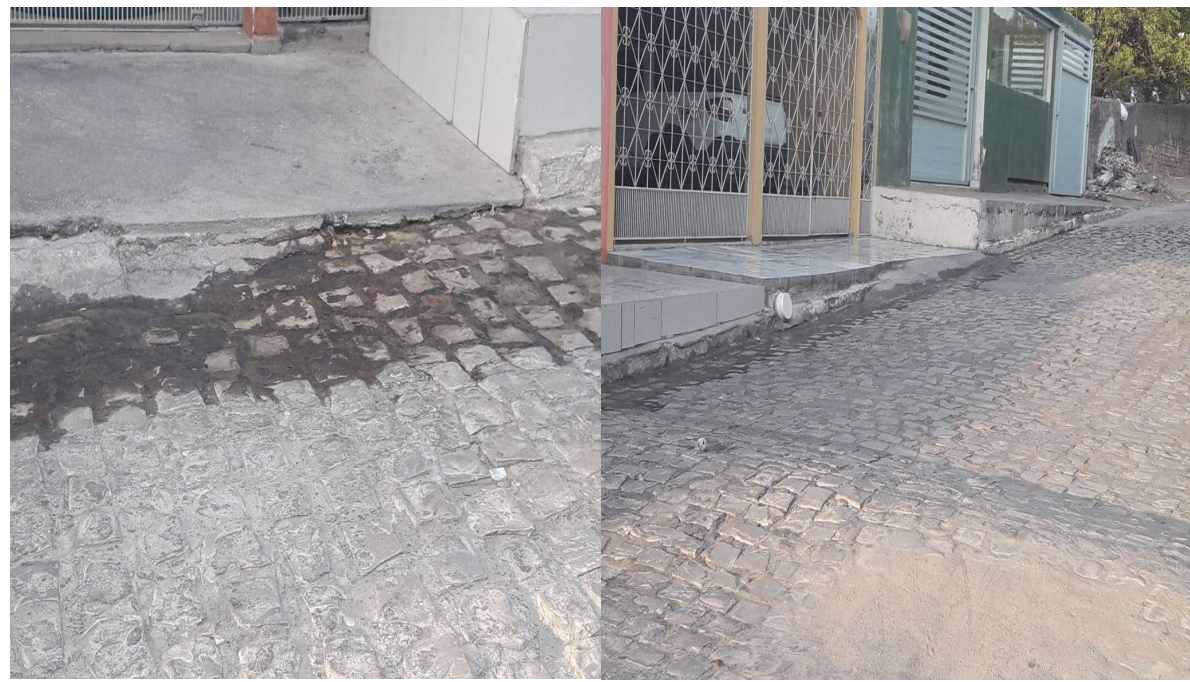

Figura 4: Vazamento de água pelas tubulações no bairro São Judas Tadeu, município de Pau dos Ferros/RN.

Quanto em esfera municipal, o valor médio de ISAA foi de 0,30, sendo assim, classificada como nível baixo satisfação. De forma semelhante, no estudo de Menezes Filho et al. (2017), com relação ao ISAA do município de Rio Paranaíba/MG, verificou-se também uma discrepância nos valores de classificação (média geral de 0,58$)$, sendo resultante da heterogeneidade do serviço prestado, tanto pela intermitência, como pela qualidade do abastecimento em cada bairro.

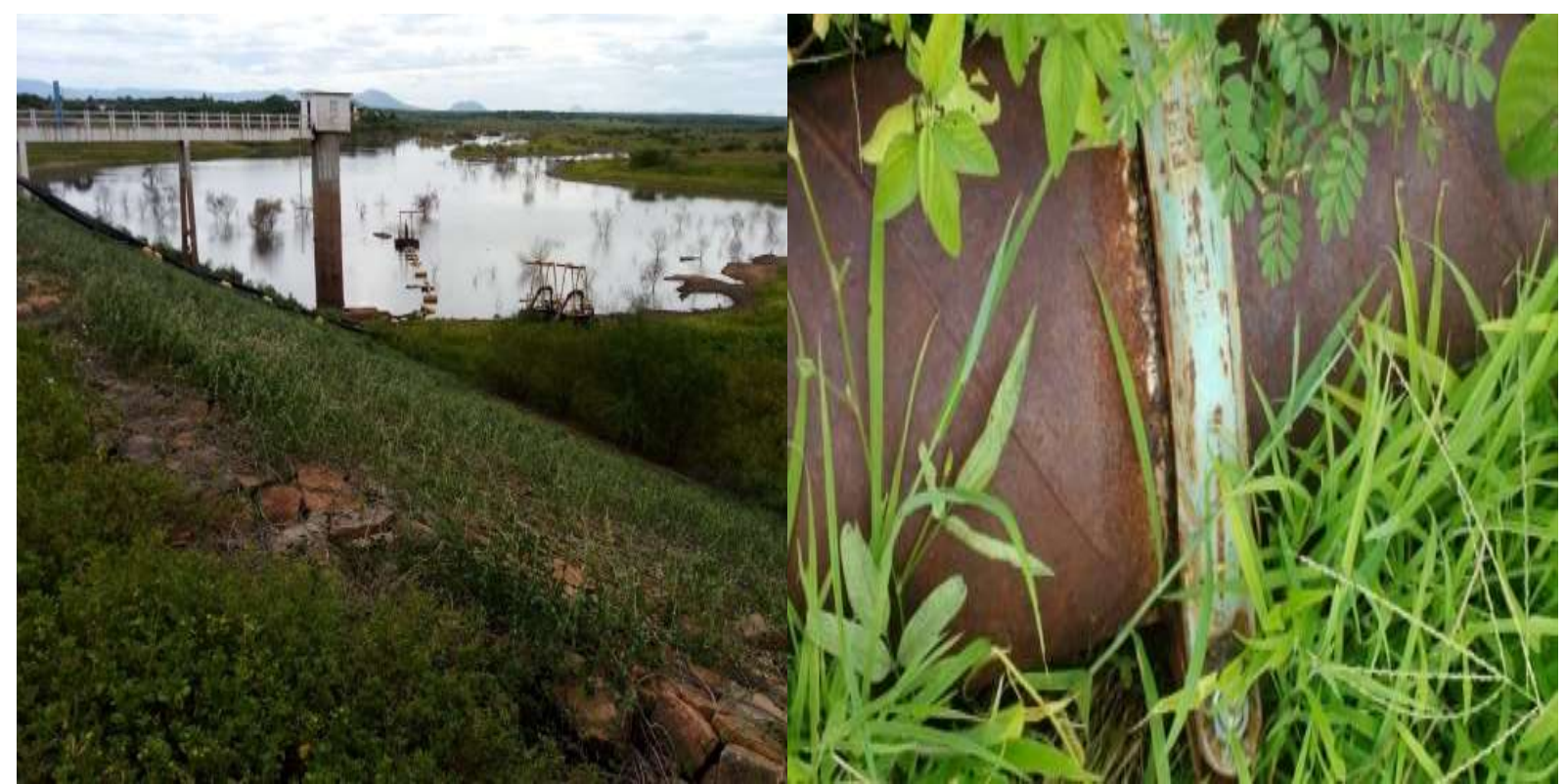

Figura 5: (a) Reservatório de água Dr. Pedro Diógenes em volume morto antes do período de chuva na cidade Pau dos Ferros/RN. (b) Estado de conservação de parte da tubulação da adutora, localizada no início da cidade de Pau dos Ferros/RN, Bairro João XXIII. Fonte: Oliveira (2018).

De acordo com a Fernandes (2017), Pau dos Ferros enfrenta um colapso hídrico (Figura 5a), devido ao longo período de estiagem nos últimos anos, tendo assim como solução paliativa a adução de água de outro manancial através da implantação de uma adutora de engate rápido, inicialmente projetada para utilização em curto prazo, de que realiza o abastecimento através da divisão da cidade em setores, fornecendo através de um sistema de rodízio entre estes. Mediante o uso excessivo desta e falta de 
manutenção, a mesma sofreu processos corrosivos como nota-se na Figura 5b que prejudicaram assim o abastecimento intermitente (OLIVEIRA, 2018).

A setorização do abastecimento no município de Pau dos Ferros em período de escassez hídrica pode ter se tornado um dos fatores para a insatisfação da população com relação a esse tipo de serviço prestado, uma vez que em vários pontos da cidade a água demora a retornar, fazendo a população encontrar formas de armazená-la. Da mesma maneira, com relação a satisfação dos usuários dos serviços de abastecimento de água de Campina Grande/PB, Medeiros (2017) aponta que o longo período de escassez hídrica e racionamento foram causas para uma avaliação considerada mediana na satisfação desse serviço prestado no município.

É notório na Figura 6 que existe uma divisão do abastecimento da cidade em três setores $(1,2,3)$, ou seja, de acordo com essa logística os bairros são abastecidos de forma quinzenal através da adutora de engate rápido que utiliza o recurso do reservatório de Santa Cruz em Apodi/RN, para assim garantir uma manutenção deste serviço durante o período de estiagem (FERNANDES, 2017).

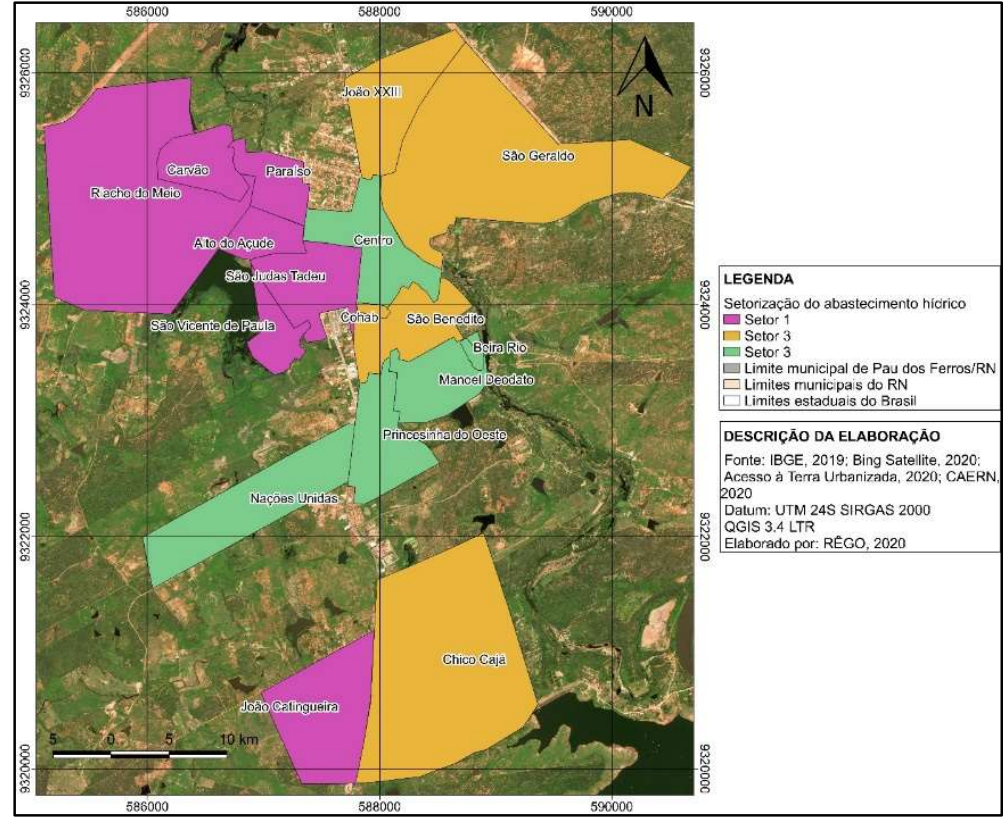

Figura 6: Espacialização da setorização do serviço de abastecimento hídrico entre os bairros da zona urbana do município de Pau dos Ferros/RN.

Embora as medidas de racionamento em regiões com escassez hídrica sejam importantes na garantia da disponibilidade de água por um maior tempo, segundo Sahin et al. (2015), a adoção de estratégias e planejamento eficaz por parte das concessionárias de água se torna indispensável na execução de infraestrutura que possa garantir o fornecimento desse recurso natural com qualidade e em quantidade suficiente, adotando alternativas viáveis, uma vez que políticas de restrição hídrica são economicamente ineficientes.

Todavia, Lima et al. (2017) relatam que, para diversos municípios do estado de Goiás, o índice de satisfação dos consumidores em relação ao abastecimento de água não está relacionado somente à eficiência do sistema de abastecimento, no entanto, se deve também às características organolépticas da água 
fornecida, como sabor/odor e limpidez, até em municípios que não realizam o processo de tratamento dessa.

Para Aisopou et al. (2012), existem diversos fatores que alteram a qualidade da água, onde variações espaciais e temporais afetam as condições físico-químicas e deterioram a qualidade dos recursos hídricos nos sistemas de abastecimento de água, sendo assim, o monitoramento dessa qualidade desde a estação de tratamento até o consumidor deve estar em conformidade aos padrões exigidos e aos níveis de orientação da Organização Mundial da Saúde (OMS). Para tanto, a avaliação periódica das características da água fornecida se torna importante para a garantia da segurança e saúde dos consumidores.

Embora tenha atingido um valor de 0,45 para o ISAA, os 21 municípios estudados na pesquisa de Lima et al. (2017) necessitam ainda realizar diversas melhorias no tratamento da água captada, assim, além dos recursos financeiros necessários, a pesquisa aponta que é indispensável ações de conscientização com a população sobre a importância da adoção de sistema de tratamento de água nos municípios que não possuem esse serviço, o que fomenta em melhores condições de vida para a própria população.

Logo, percebe-se que o abastecimento de água potável no município de Pau dos Ferros/RN apresenta-se de forma insatisfatória, de acordo com a percepção dos moradores da região. Essa situação pode ser justificada devido a inexistência de um abastecimento constante e ininterrupto, além da presença de vazamentos na rede de abastecimento em alguns bairros da cidade. Assim, a administração pública juntamente com a companhia de abastecimento deve desenvolver ações que visem melhorar esse serviço, dentre elas, investimento em equipamentos, monitoramento de vazamentos externo e internos, dentre outros.

\section{CONCLUSÕES}

O baixo índice de satisfação de abastecimento de água de 0,30 deve-se principalmente a fatores como período de estiagem prolongado, que levou a necessidade de racionar e setorizar o serviço. Ainda atrelado a esses fatores, têm-se os topográficos e de dimensionamento de distribuição hídrica, que ocasionam diferenças significativas na vazão de abastecimento por bairros.

Diante de tal cenário, verificou-se a necessidade de criar um plano mais preciso de gestão hídrica e necessidade de investimentos voltados a implantação de obras mais diretivas para a melhorar a eficiência destes serviços básicos em todas as áreas da cidade, e com isso proporcionar uma maior qualidade de vida a todos os cidadãos.

Espera-se que essa pesquisa contribua como material teórico para compreensão da satisfação da população da zona urbana de Pau dos Ferros/RN em relação aos serviços do sistema de abastecimento hídrico. Assim como, fornecer subsídios para elaboração de ações gerenciais e/ou intervenções que visem melhorias do serviço oferecido a população do município supracitado e um correto direcionamento dos recursos disponibilizados, especialmente em bairros onde o índice de satisfação se demonstrou mais baixo, para que assim haja uma efetiva melhoria da qualidade de vida dos moradores dessa localidade. 


\section{REFERÊNCIAS}

AISOPOU, A.; STOIANOV, I.; GRAHAM, N. J.. In-pipe water quality monitoring in water supply systems under steady and unsteady state flow conditions: A quantitative assessment. Water Research, v.46, n.1, p.235-246, 2012. DOI: https://doi.org/10.1016/j.watres.2011.10.058

ANDRADE, L. R. S.; BARBOSA, R. F.; ALEXANDRE, S. N.; FEITOSA, P. H. C.. Universalização do serviço de abastecimento de água na percepção do usuário no município de Itapororoca (PB). Revista Ibero-Americana de Ciências Ambientais, v.10, n.4, p.289-300, 2019. DOI: https://doi.org/10.6008/CBPC2179-6858.2019.004.0022

BRASIL. Ministério do Desenvolvimento Regional. Secretaria Nacional de Saneamento. Sistema Nacional de Informações sobre Saneamento: 24ํ Diagnóstico dos Serviços de Água e Esgotos, 2018. Brasília: SNS, 2019.

CUNHA, M. C.; CANAN, B.. Percepção ambiental de moradores do bairro nova Parnamirim em Parnamirim/RN sobre saneamento básico. HOLOS, v.1, p.133-143, 2015. DOI: https://doi.org/10.15628/holos.2015.2253

DANTAS, J. R. Q.; CLEMENTINO, M. L. M.; FRANÇA, R. S.. A cidade média interiorizada: Pau dos Ferros no desenvolvimento regional. Revista Tecnologia e Sociedade, Curitiba, v.11, n.23, p.129-148, 2015.

FERNANDES, C.. Dinâmica urbana e os rebatimentos da escassez hídrica em Pau dos Ferros/RN. Dissertação (Mestrado em Planejamento e Dinâmicas Territoriais no Semiárido) - Universidade do Estado do Rio Grande Do Norte, Pau dos Ferros, 2017.

GIL, A. C.. Como elaborar projetos de pesquisa. 4 ed. São Paulo: Atlas, 2008.

IBGE. Instituto Brasileiro de Geografia e Estatística. Pesquisa nacional por amostra de domicílios contínua (2012-2016): PNAD CONTÍNUA. Brasília: IBGE, 2017.

LEITE, L. R. M.; MOURA, B. M. D.. Caracterização do consumo percapita e do uso da água da população de Pau dos Ferros/RN. Holos Environment, v.19, n.4, p.640-656, 2019. DOI: http://dx.doi.org/10.14295/holos.v19i4.12356

LIBANIO, P. A. C.; CHERNICHARO, C. A. L.; NASCIMENTO, N. O.. A dimensão da qualidade de água: avaliação da relação entre indicadores sociais, de disponibilidade hídrica, de saneamento e de saúde pública. Engenharia Sanitária e Ambiental, Rio de Janeiro, v.10, n.3, p.219-228, 2005. DOI: https://doi.org/10.1590/S1413-41522005000300006

LIMA, A. S. C.; SCALIZE, P. S.; ARRUDA, P. N.; BAUMANN, L. R. F.. Satisfação e percepção dos usuários dos sistemas de saneamento de municípios goianos operados pelas prefeituras. Engenharia Sanitária e Ambiental, Rio de Janeiro, v.22, n.3, p.415-428, 2017. DOI: https://doi.org/10.1590/s1413-41522017142945

LIMA, T. B. R.. Resposta hidrológica de uma grande bacia hidrográfica no semiárido brasileiro diante de cenários de transposição hídrica e racionalização do uso de reservatórios não estratégicos. Dissertação (Mestrado em
Engenharia Agrícola) - Universidade Federal do Ceará, Fortaleza, 2020.

MARCONI, M. A.; LAKATOS, E. M.. Fundamentos de metodologia científica. 7 ed. São Paulo: Atlas, 2010.

MARTINS, G. A.. Estatística geral e aplicada. 3 ed. São Paulo: Atlas, 2006

MARTINS, E. S. P. R.; MAGALHÃES, A. R.. A seca de 20122015 no Nordeste e seus impactos. Parcerias Estratégicas, v.20, n.41, p.107-128, 2016

MEDEIROS, L. E. L.. Utilização de indicadores convencionais e de satisfação dos usuários para avaliação da qualidade do serviço de abastecimento de água na cidade de Campina Grande/PB. Dissertação (Mestrado em Engenharia Civil e Ambiental) - Universidade Federal de Campina Grande, Paraíba, 2017.

MENEZES FILHO, F. C. M.; RODRIGUES, A. L. M.. Avaliação do saneamento ambiental por meio da proposição e aplicação de índices de percepção e satisfação populacional. Holos Environment, v.17, n.1, p.122-137, 2017. DOI: http://dx.doi.org/10.14295/holos.v17i1.12177

MOTTA, R. G.. Importância da setorização adequada para combate às perdas reais de água de abastecimento público. Dissertação (Mestrado em Engenharia Hidráulica) Universidade de São Paulo, São Paulo, 2010. DOI: https://doi.org/10.11606/D.3.2010.tde-18082010-171334

OLIVEIRA, M. P.. Análise do processo corrosivo em dutos de ferro: um estudo de caso na adutora de Pau dos Ferros/RN. Monografia (Bacharelado em Ciência e Tecnologia) - Universidade Federal Rural do Semiárido, Pau dos Ferros, 2018.

PRODANOV, C. C.; FREITAS, E. C.. Metodologia do trabalho científico: métodos e técnicas da pesquisa e do trabalho acadêmico. Novo Hamburgo: FEEVALE, 2013.

RIBEIRO, L. G. G.; ROLIM, N. D.. Planeta água de quem e para quem: uma análise da água doce enquanto direito fundamental e sua valoração mercadológica. Revista Direito Ambiental e Sociedade, v.7, n.1, 2017.

RONCALLI, A. G.; NORO, L. R. A.; CURY, J. A.; ZILBOVICIUS, C.; PINHEIRO, H. H. C.; ELY, H. C.; NARVAI, P. C.; FRAZÃO, P.. Fluorización del agua en Brasil: distribución regional y exactitud de la información sobre su vigilancia en municipios con más de 50 mil habitantes. Cadernos de Saúde Pública, v.35, n.6, 2019. DOI: https://doi.org/10.1590/0102$\underline{311 \times 00250118}$

SAHIN, O.; STEWART, R.A.; PORTER, M. G.. Water security through scarcity pricing and reverse osmosis: a system dynamics approach. Journal of cleaner production, v.88, p.160-171, 2015. DOI: https://doi.org/10.1016/i.jclepro.2014.05.009

SALDANHA, H. G. A. C.; MELO, W. F.; MELO, L. P. M.; ALMEIDA, K. M.; SOUZA, E. A.; RODRIGUES, L. M. S.; MEDEIROS, A. C.; MELO, W. F.. A qualidade da prestação de 
serviços de abastecimento de água para consumo humano: revisão bibliográfica. Informativo Técnico do Semiárido, v.10, n.1, p.18-27, 2016.

SILVA, I. M. G.; GRANZIERA, M. L. M.. Os Objetivos de Desenvolvimento Sustentável (ODS) e a Legislação Brasileira Sobre Abastecimento Humano: Mecanismos de Efetividade. Leopoldianum, v.45, n.125, p.125-136, 2019.
TEIXEIRA, M. A. M.; FERRO, M. M.. I-319-gestão de perdas em sistemas de abastecimento de água por meio de distrito de medição e controle (DMC) e modelagem hidráulica computacional: estudo de caso do DMC José Lages em Maceió/AL. In: CONGRESSO BRASILEIRO DE ENGENHARIA SANITÁRIA E AMBIENTAL, 30. Anais. Natal: ABES, 2019.

A CBPC - Companhia Brasileira de Produção Científica (CNPJ: 11.221.422/0001-03) detém os direitos materiais desta publicação. Os direitos referem-se à publicação do trabalho em qualquer parte do mundo, incluindo os direitos às renovações, expansões e disseminações da contribuição, bem como outros direitos subsidiários. Todos os trabalhos publicados eletronicamente poderão posteriormente ser publicados em coletâneas impressas sob coordenação da Sustenere Publishing, da Companhia Brasileira de Produção Científica e seus parceiros autorizados. Os (as) autores (as) posteriormente ser publicados em coletâneas impressas sob coordenação da Sustenere Publishing, da Companhia Brasileira de Produção Científica e seus par
preservam os direitos autorais, mas não têm permissão para a publicação da contribuição em outro meio, impresso ou digital, em português ou em traduçãa. 